\title{
Correction to: Debiasing versus knowledge retrieval checklists to reduce diagnostic error in ECG interpretation
}

\author{
Matt Sibbald ${ }^{1,2}$ D . Jonathan Sherbino ${ }^{2}$ Jonathan S. Ilgen ${ }^{3} \cdot$ Laura Zwaan $^{4}$. \\ Sarah Blissett ${ }^{5} \cdot$ Sandra Monteiro ${ }^{1,2,6} \cdot$ Geoffrey Norman ${ }^{2,6}$
}

Published online: 26 March 2019

(c) Springer Nature B.V. 2019

\section{Correction to: Advances in Health Sciences Education https://doi.org/10.1007/s10459-019-09875-8}

Due to an unfortunate turn of events, Fig. 3 was omitted from the original publication. Hence, the first line underneath the heading 'Effect of instructional condition on errors and time' in the 'Results' section incorrectly states that:

"The error rates for junior and senior learners by condition are shown in Fig. 2."

This should read:

"The error rates for novice and experienced learners by condition are shown in Fig. 3."

Figure 3 and its caption are published here and should be treated as definitive.

The original article can be found online at https://doi.org/10.1007/s10459-019-09875-8.

Matt Sibbald

Sibbald@mcmaster.ca

1 Department of Medicine, Centre for Simulation Based Learning, McMaster University, 1200 Main St W, Hamilton, ON, Canada

2 McMaster Faculty of Health Sciences Education Research, Innovation and Theory Program, McMaster University, Hamilton, Canada

3 Department of Emergency Medicine and Center for Leadership and Innovation in Medical Education, University of Washington, Seattle, USA

4 Institute of Medical Education Research Rotterdam, Erasmus MC, Rotterdam, The Netherlands

5 University of California, San Francisco, USA

6 Department of Health Research Methods, Evidence and Impact, McMaster University, Hamilton, Canada 


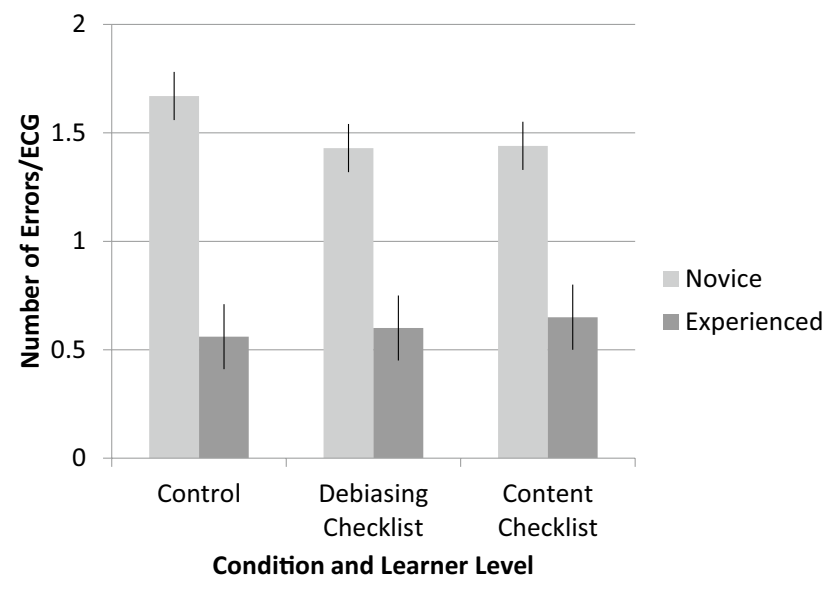

Fig. 3 Number of errors/ECG by educational level and instructional condition (control, cognitive bias checklist, content checklist)

Publisher's Note Springer Nature remains neutral with regard to jurisdictional claims in published maps and institutional affiliations. 